\title{
MEDIDA DO TEMPO MÁXIMO DE FONAÇÃO DE PROFESSORAS DO MUNICÍPIO DE NITERÓI/RJ
}

\section{Maximum phonation time measure of teachers in Niterói/RJ}

\author{
Rosangela Alves de Mendonça ${ }^{(1)}$, Tânia Maria Marinho Sampaio ${ }^{(2)}$, Lúcia Provenzano ${ }^{(3)}$
}

\section{RESUMO}

Objetivo: medir os limites do tempo máximo de fonação pré e pós-aplicação do Programa de Exercícios Funcionais Vocais de Stemple e Gerdeman em professoras, com e sem alteração vocal, que atuam no ensino fundamental do Município de Niterói-RJ. Método: participaram do estudo 17 professoras, que aceitaram participar espontaneamente da aplicação do programa de exercícios: vogal /i/ sustentada, glissando ascendente e descendente da palavra /nol/, e escala de tons musicais Dó,Ré,Mi,Fá,Sol, com emissão de /ol/, pelo tempo máximo de fonação. A medida do tempo foi coletada pré e pós-aplicação do programa por meio da vogal [ع], após a participante ter sido submetida a exame de videolaringoestroboscopia. Resultados: verificou-se expressivo ganho do tempo máximo de fonação do pré para o pós-exercício e o valor do programa, que em sua aplicação, prioriza a execução dos exercícios com o maior tempo possível de fonação. Conclusão: o Programa de Exercícios Funcionais Vocais de Stemple e Gerdeman favoreceu o aumento do tempo máximo de fonação intrassujeito, possibilitando melhores condições de saúde vocal no desempenho profissional e social.

DESCRITORES: Voz; Fonação; Treinamento da Voz

\section{INTRODUÇÃO}

A avaliação funcional da voz inclui medidas respiratórias, como o tempo máximo de fonação (TMF), tanto na avaliação quanto na terapia fonoaudiológica. Este tempo, aferido em segundos, consiste de uma medida acústica complementar e tem demonstrado sua validade entre adultos, por se tratar do tempo máximo em que o sujeito pode sustentar um som, numa só expiração ${ }^{1,2}$, envolvendo os subsistemas fonatório e respiratório.

(1) Fonoaudióloga da Fundação de Apoio das Escolas Técnicas do Rio de Janeiro - FAETEC/RJ e da Fundação Municipal de Educação de Niterói/RJ; Coordenadora da Unidade de Saúde Escolar do CETEP-Barreto/Niterói; Mestre em Fonoaudiologia Profissionalizante pela Universidade Veiga de Almeida.

(2) Graduação em Letras pela Universidade Federal do Rio de Janeiro; Professora da Universidade Veiga de Almeida e da Universidade Federal Fluminense; Doutora em Filosofia pela Universidade Gama Filho.

(3) Fonoaudióloga da Fundação de Apoio das Escolas Técnicas do Rio de Janeiro - FAETEC/RJ; Professora assistente da Universidade UniRio; Mestre em Fonoaudiologia Profissionalizante pela Universidade Veiga de Almeida.

Conflito de interesses: inexistente
O TMF permite observação quanti-qualitativa do som² $^{2}$. Medida indireta e confiável que quantifica a ação muscular e muco-ondulatória das pregas vocais e o fluxo de ar dos pulmões, refletindo as condições físicas e funcionais do sujeito; ou seja, possibilita verificar a habilidade da glote em manter-se fechada e indicará se o paciente está em condições de controlar as forças aerodinâmicas da corrente pulmonar e as forças mioelásticas da laringe $\mathrm{e}^{2-4}$

Os mesmos autores ${ }^{1,2}$ observaram que, quando o TMF é reduzido, pode haver relato por parte do profissional da voz de momentos inesperados de ausência de sonorização na fala espontânea. $O$ esforço vocal, pressão de ar ou aproximação insuficiente das pregas vocais, para compensar as demandas vocais, são outras possibilidades de redução do TMF.

Alguns autores ${ }^{2,5}$ consideram valores médios do TMF ao redor de 14 segundos para mulheres e, o adotam como um teste de eficiência glótica na sustentação das vogais, em frequência e intensidade habituais.

Indivíduos com técnica vocal inadequada utilizam o TMF entrando no ar de reserva expiratória, 
realizando diversas inspirações, muitas vezes longas, com esforço muscular e pouca eficiência na coordenação pneumofônica. Quando a função fonatória estiver comprometida, haverá uma redução na quantidade de ar disponível para apoiar a fonação, o que consiste um problema no fluxo de ar. Se a questão é a nível laríngeo, a resistência glótica ao fluxo de ar pode ser reduzida devido a um fechamento glótico inadequado, incompleto, ou aumentado devido à obstrução ou hiperadução da glote ${ }^{1}$. Este mecanismo de produção vocal é complexo e exige interação de diversos sistemas do organismo, desde o trato respiratório até o sistema nervoso central.

O propósito deste trabalho foi comparar os TMF de professoras da Rede de Educação Municipal de Niterói antes e após a realização do programa de exercícios funcionais vocais de Stemple e Gerdeman ${ }^{6}$.

\section{MÉTODO}

Trata-se de um estudo transversal, exploratório, não experimental, quantitativo de dados obtidos no artigo publicado "Avaliação do programa de Exercícios Funcionais Vocais de Stemple e Gerdeman em professores"7, coleta realizada em professores da Rede Pública Municipal de Niterói - Rio de Janeiro.

A metodologia estatística já utilizada no referido artigo "Avaliação do Programa de Exercícios Funcionais Vocais de Stemple e Gerdeman em Professores" é aqui revista e retomada como foco central do presente estudo, que objetiva, destacadamente, o confronto do TMF entre as fases pré e pós-exercícios funcionais vocais.

As dezessete (17) participantes foram avaliadas quanto do TMF e, em seguida participaram do Programa por um período de dois meses, entre julho e dezembro de 2008.

O critério de inclusão das docentes foi pautado no resultado da vídeoendoscopia laríngea normal ou com presença de fendas glóticas, de nódulos, de edemas e de hiperemias de prega vocal. Foram excluídas da amostra professoras com paresias, paralisias, leucoplasias, sulcos e pólipos.

As medidas do TMF foram colhidas com as professoras sentadas e orientadas a inspirarem pelo nariz e emitirem o fonema $[\varepsilon]$, em tom, intensidade e velocidade habituais, sustentando o tempo máximo possível na mesma expiração, por duas vezes, para extração da média. Foi considerado o valor de 14 segundos como referência ${ }^{2}$, para falantes adultos femininos normais e utilizado um cronômetro digital da marca Mondaine profissional.

O Programa de Exercícios Funcionais Vocais ${ }^{7}$ foi aplicado individualmente com um (1) encontro semanal, num total de oito (8) encontros, com a seguinte sequência de exercícios: Exercício 1 - emissão da vogal [i:] na nota musical $\mathrm{Fa}_{3}$ pelo TMF numa intensidade confortável, direcionando a ressonância rinofaríngea. Exercício 2 - emissão de glissando ascendente da palavra [nol:], do som grave para os tons agudos. Exercício 3 - emissão de glissando descendente da palavra [nol:], do som agudo para os tons graves. Exercício 4 - manutenção do som [ol:] em cada nota Dó ${ }_{3}, \mathrm{Ré}_{3}, \mathrm{Mi}_{3}$, $\mathrm{Fá}_{3}, \mathrm{Sol}_{3}$. A todas as participantes foi entregue na semana 1, o CD áudio, para o devido acompanhamento diário.

A pesquisa relativa ao supracitado artigo foi aprovada pelo Comitê de Ética resolução sob número 092/07 da Universidade Veiga de Almeida-RJ, o que conclusivamente se estende à retomada das suas questões no atual aprofundamento.

Os resultados foram analisados utilizando o teste "t" de Student, por se tratar de experimento em que se observam os mesmos indivíduos duas vezes, uma vez antes, outra vez após o tratamento. O teste é significante ao nível de tolerância de erros em $1 \%$, ou seja, existe diferença significaiva entre os dois grupos pré e pós, quando o valor calculado for superior a "t"= 2,92.

\section{RESULTADOS}

O tratamento estatístico dos valores do TMF da vogal [ $\varepsilon$ :] foi analisado em segundos, pré e pós-aplicação do programa.

Após cálculo de cada média aritmética do TMF do pré e do pós-programa, obtiveram-se as diferenças da vogal $[\varepsilon]$ de 4,41 segundos. No tratamento estatístico, o valor de " $\mathrm{t}$ ", para análise do TMF, foi calculado em 9,09 segundos, no grupo pesquisado. Foi, portanto, superior ao valor de "t" da tabela de Student 2,92, levando-se à conclusão de que após aplicação dos exercícios obteve-se efeito significante sobre o TMF, pré e pós-Programa de Exercícios.

Ampliando a constatação estatística, e dirigindo o foco especificamente à tabela relativa à aplicação pré e pós da pesquisa, observa-se que nenhuma das participantes apresentou o TMF abaixo de 10 segundos e todas aumentaram seu tempo de fonação pós Programa, de 2 a 8 segundos. Considerando o tempo de dois meses relativo aos exercícios, os resultados se expressam com grande significância.

Das 17 participantes, 6 apresentaram, no pós-treinamento, TMF dentro e acima do padrão médio esperado, de 14 segundos; as demais obtiveram entre 10 e 14 segundos, levando-se em consideração que os valores iniciais foram bastante baixos, 
a saber, de 5 a 8 segundos. Cabe ressaltar que o tempo de fonação abaixo de 10 segundos é considerado aquém em algumas pesquisas que balizam o valor abaixo de 10 segundos como negativo demonstrando comprometimento no suporte respiratório ${ }^{1,2,8-10}$.

Tabela 1 - Tempo Máximo de Fonação da vogal [ع] pré e pós com a diferença

\begin{tabular}{cccc}
\hline Participante & $\begin{array}{c}\text { TMF - Pré } \\
\text { (em segundos) }\end{array}$ & $\begin{array}{c}\text { TMF - Pós } \\
\text { (em segundos) }\end{array}$ & $\begin{array}{c}\text { Diferença } \\
\text { (pré-pós) }\end{array}$ \\
\hline 01 & 6 & 11 & 5 \\
02 & 10 & 14 & 4 \\
03 & 8 & 12 & 4 \\
04 & 12 & 19 & 7 \\
05 & 9 & 11 & 2 \\
06 & 6 & 13 & 7 \\
07 & 8 & 15 & 7 \\
08 & 5 & 10 & 5 \\
09 & 6 & 11 & 5 \\
10 & 8 & 10 & 2 \\
11 & 15 & 23 & 8 \\
12 & 14 & 18 & 4 \\
13 & 8 & 13 & 5 \\
14 & 15 & 17 & 2 \\
15 & 8 & 10 & 2 \\
16 & 8 & 12 & 4 \\
17 & 9 & 11 & 2 \\
\hline
\end{tabular}

\section{DISCUSSÃO}

Este estudo difere das demais pesquisas que tem o valor 14 segundos como padrão. Na presente análise, foi adotada a "quebra" da dureza do padrão e valorizada especificamente a variação, esta significante e relativa à contextualização do grupo analisado. A postura do senso do relativismo dirigido e refletido nos seus próprios resultados é que garantiram o êxito do trabalho realizado. Mergulhando na auto-análise destes resultados, percebe-se a diferença que nos posicionaram aquém dos padrões estabelecidos, porém bastante além dos inícios e dos patamares relativos à instância pré-exercícios deste grupo.

A validar a postura relacional e o sentido enfatizado na vivência processual do programa terapêutico que em si denotou o tamanho desenvolvimento alcançado pelo grupo, embora apresente resultados abaixo dos valores adotados e estabelecidos em conformidade às pesquisas aludidas quanto aos resultados ${ }^{1,2,9,10}$.

Os benefícios relativos a melhores condições de saúde vocal no desempenho profissional e social a partir do aumento do TMF foram observados, durante e após a aplicação do programa, embora com medidas aquém dos valores padronizados e absolutos sugeridos pela literatura.

Endossando a argumentação quanto à observação de pesquisas que objetivaram tomar medidas do TMF, que também apresentaram resultados aquém dos padrões estabelecidos, Miglioranziii ${ }^{9}$ constatou, em seu artigo, que o TMF da vogal $[\varepsilon] \mathrm{em}$ sua amostra foi de 10,43s segundos, encontrando-se reduzido em relação ao referido padrão. Confirmando ainda a mesma questão, pesquisas ${ }^{10-12}$ verificaram que o TMF é significantemente menor que o proposto pela literatura, evidenciando que com lesão, como o nódulo ou não, ocorrem alterações na firmeza glótica, tornando-se necessário o redirecionamento da pressão aérea para o inicio e manutenção da fonação ${ }^{13,14}$.

É, pois, realçada e colocada em questão a singularidade e a expressividade dessa pesquisa que aponta para o ganho maior obtido por meio da aplicação do programa Stemple e Gerdeman, não se limitando à tomada dos dados e medidas, mas sim à transformação desses dados por meio dos exercícios que aumentaram a projeção vocal e a resistência glótica dos professores avaliados. 
Todas as participantes foram beneficiadas com a obtenção do aumento do TMF, após a aplicação dos Exercícios funcionais vocais. Assim, a eficiência da coordenação existente entre os sistemas respiratório e fonatório para a produção máxima da fonação, realizada por meio da aplicação do Programa, possibilitaram às participantes melhorar o seu tempo de fonação, levando-as a diminuir as tomadas de ar a cada emissão, o que acabava provocando esforço e fadiga vocal.

\section{CONCLUSÃO}

Verificou-se aumento significante do TMF do pré para o pós-programa de exercícios funcionais vocais, que em sua aplicação prioriza a execução dos exercícios com o maior tempo possível de fonação, oferecendo melhores condições de saúde vocal para o desempenho profissional e social.

\begin{abstract}
Purpose: to measure the limits of the maximum phonation time pre and post application of the Stemple and Gerdeman Vocal Function Exercises Program in teachers of the Elementary School Education level in Niterói/Brazil, with or without voice alterations. Method: there were 17 female teachers who spontaneously agreed to participate. The exercise program that was applied consisted in the sustained vowel /i/, ascending and descending gliding on the word /nol/, and musical scale tones Do Re Mi Fa Sol - issuing the /ol/ for the maximum time of phonation. The measure of the maximum phonation time was counted pre and post exercise program through the vowel /ع/. Results: the results revealed that the teachers presented an expressive increase in the maximum phonation and time duration of the post-exercise program. Conclusion: the Stemple and Gerdeman Vocal Function Exercise Program applied to teachers enhanced their professional performance increasing the maximum phonation time intrasubjects.
\end{abstract}

KEYWORDS: Voice; Phonation; Voice Training

\section{REFERÊNCIAS}

1. Colton $\mathrm{RH}$, Casper JK. Compreendendo os problemas de voz. Porto Alegre: Artes Médicas; 1996.p 28 e p.222.

2. Behlau M, Madazio G, Feijó, pontes P. Avaliação da Voz. In: Behlau m, organizadora, Voz: o livro do especialista. V. 1. Rio de Janeiro: Revinter; 2001. P.105.

3. Solomon NP, Garlitz SJ, Milbrath RL. Respiratory and Laryngeal Contributions to Maximum Phonation Duration. Journal of Voice. 2000;14(3):331-40.

4. Mehta DD, Hillman RE. Voice Assessment: updates on perceptual, acoustic, aerodynamic, and endoscopic image methods. Current Opinion in Otolaryngology and Head and Neck Surgery. 2008;16(3):211-5.

5. Zemlim WR. Mecânica da Respiração. Porto Alegre: artmed; 2002. P 94-113.

6. Stemple JC, Glaze LE, Gerderman BK. Clinical voice pathology: theory and management. San Diego: Singular Publishing Group; 2000.
7. Mendonça RA, Sampaio TMM, Oliveira DSF. Avaliação do Programa de Exercícios Funcionais Vocais de Stemple e Gerdeman em Professores. Rev CEFAC. 2010;12(3):471-82.

8. Gonçalves MIR, Pontes PAL, Vieira VP, Pontes AAF, Curcio D, Biase NG. Função de transferência das vogais orais do português brasileiro: análise acústica comparativa. Braz. J. otorhinolaryngol.2009;75(5):680-4.

9. Miglioranzi SLI, Cielo CA, Siqueira MA. Relação entre capacidade vital, e tempos máximos de fonação de /e/ emitido de forma áfona, de /s/ e estatura em mulheres adultas. Rev. CEFAC. 2011;12(4):110-5.

10. Soares EB, Brito CMCP. Perfil Vocal do Guia de turismo. Rev CEFAC. 2006;8(4):501-8.

11. Kurtz LO, Cielo CA. Tempos Máximos de fonação de vogais em mulheres adultas com nódulos vocais. Pró-Fono R. Atual. Cient. 2010;22(4):451-4.

12. Valim MA, Santos RS, Filho EDM, Abdulmassih EMS, Serrato MRF. A relação entre o tempo máximo de fonação, freqüência fundamental e a proteção de Vias aéreas. RBORL. 2007;11(3):437. 
13. Cielo CA, Lasch SS, Miglioranzi SL, Conterno G. Tempo máximo de fonação e características vocais acústicas de mulheres com nódulos vocais. Rev. CEFAC [online]. 2011;13(3):437-43.
14. Dejonckere $\mathrm{PH}, \mathrm{Kob} \mathrm{M}$. Pathogenesis of vocal fold nodules: New insights from a modeling approach. Folia phoniatr logop.2009;61(3):171-9.

http://dx.doi.org/10.1590/S1516-18462012005000103

RECEBIDO EM: 27/08/2011

ACEITO EM: 02/02/2012

Endereço para correspondência:

Rosangela Alves de Mendonça

Rua Geógrafo Amora, 501 - A15 - Piratininga

Niterói - RJ - Brasil

CEP: $24350-590$

E-mail: rosangelamendonc@gmail.com

Rev. CEFAC. 2012 Nov-Dez; 14(6):1204-1208 